\title{
A relação pai-bebê: o olhar de mães usuárias de um serviço de saúde materno-infantil
}

\author{
Dorian Monica Arpini* \\ Edinara Zanatta** \\ Rafaela Quintana Marchesan*** \\ Suane Pastoriza Faraj**** \\ Carolina Sarzi Ledur***** \\ Caroline Rossato Pereira******
}

\begin{abstract}
Resumo
Este estudo objetivou refletir acerca da relação inicial pai-bebê, tendo como referência depoimentos de mães de bebês atendidos em um serviço de saúde materno-infantil. Participaram do estudo onze mães cujos bebês encontravam-se na faixa etária de zero a oito meses incompletos, residentes em uma cidade do interior do estado do Rio Grande do Sul. Os dados foram coletados através de entrevistas semiestruturadas realizadas com cada uma das mães individualmente. Através do relato das mães, pôde-se perceber que para elas há uma relação afetiva estabelecida entre pai e filho desde os primeiros meses do bebê. As mães parecem considerar a importância do pai para o filho, permitindo e possibilitando que ele ocupe um lugar significativo na vida do bebê. Tais achados apontam para a importância de práticas em promoção de saúde que acolham e incluam a demanda paterna, integrando o pai no contexto de acompanhamento da saúde do bebê.
\end{abstract}

Descritores: paternidade; relações familiares; desenvolvimento infantil; promoção da saúde.

\begin{abstract}
This study aimed to reflect on the early father-child relationship, based on reports from mothers of babies seen at a maternal and child health service. Eleven mothers whose babies were aged zero to eight months incomplete participated in the study. The participants lived in a city in the countryside of Rio Grande do Sul. Data were collected through semi-structured interviews conducted with each mother individually. Through mothers report, it could be noticed that for them there is a father-child emotional bond established since baby's first months. Mothers seemed to believe that the father is important to the child, allowing and enabling him to occupy a significant place in baby's life. These findings point the importance of health promotion practices that welcome and include paternal demands, integrating the father in the context of monitoring baby's health.

Index Terms:paternity; family relations; child development; health promotion.
\end{abstract}

* Psicóloga, Docente do Departamento de Psicologia e do Programa de Pós-Graduação em Psicologia da UfSM. Tutora de Residência Multiprofissional Integrada em Sistema Público de Saúde da UFSM.

** Psicóloga pela UFSM e Mestre em Psicologia pela UFSM.

***Psicóloga pela UFSM, Mestranda em Psicologia da UFSM.

****Psicóloga e Mestre em Psicologia pela UFSM.

*****Psicóloga pela UFSM e bolsista de IC Pibic/CNPQ.

******Psicóloga, Docente do Departamento de Psicologia de Pós-Graduação em Psicologia da UFSM. 


\section{Introdução}

Sabe-se que durante muito tempo a tarefa de cuidado para com os filhos foi reconhecida como uma atividade destinada às mães, sendo essas tomadas como referência principal para os estudos envolvendo a temática do cuidado com os bebês (Dias \& Aquino, 2006). De acordo com Muza (1998), o pouco envolvimento paterno decorria das exigências nas relações sociais, tendo como consequência, o convívio familiar abdicado em favor do trabalho. Contudo, com as transformações no papel do pai e no relacionamento com os filhos, fez-se necessário rever essas escolhas, especialmente no que concerne ao significado da função paterna (Ramires, 2014).

Nesse contexto, a década de 50 marcou o início dos investimentos em estudos acerca do papel paterno, da constituição do vínculo e do relacionamento pai-filho (Benczik, 2011). Pode-se apontar que as mudanças sociohistóricas que se fizeram presentes, sobretudo na década de 1960 e 1970, como o movimento feminista, a massiva inserção das mulheres no mercado de trabalho, o surgimento da pílula anticoncepcional, entre outros, trouxeram alterações nos papéis familiares (Amiralian, 2014; Silva, 2007; Roudinesco, 2003). Desse modo, observou-se uma crescente flexibilização do papel do homem na família e na sociedade, sendo as funções de provimento econômico e de autoridade ampliadas para uma maior participação na rotina, na interação e nos cuidados com as crianças (Ramires, 2014; Souza \& Benetti, 2009; Staudt \& Wagner, 2008; Wagner, Predtebon, Mosmann, \& Verza, 2005).

Tais redefinições dos papéis familiares e a ampliação da participação paterna no cuidado com os filhos têm impulsionado a realização de estudos sobre a paternidade (Amiralian, 2014; Gomes \& Resende, 2004; Saraiva, Reinhard \& Souza, 2012; Silva \& Piccinini, 2007; Wendland, 2001; Sutter \& Bucher-Maluschke, 2008), sobretudo nas últimas duas décadas (Nelson, 2004). Esses estudos têm evidenciado um encorajamento por parte dos pais de incluir em suas tarefas a manifestação do afeto, da ternura e dos cuidados cotidianos na rotina com o bebê, aproximando o pai e o bebê desde o início desta relação (Ramires, 2014; Saraiva, Reinhard \& Souza, 2012).

Em relação aos aspectos psicológicos concernentes ao desenvolvimento inicial da criança, Aberastury e Salas (1984) destacaram, a partir da década de 80, a importância da participação paterna. Embora tenham ressaltado ser inegável a importância da mãe para o desenvolvimento da criança, assinalaram que o pai também possui papéis fundamentais a serem desempenhados, entre eles o de romper o vínculo narcísico mãe-filho, interditando a re- lação incestuosa, e deixando como herança o Complexo de Édipo (Julien, 2000; Silva, 2007). Nesse sentido, em concordância com Silva (2007), a função paterna apresenta-se como indispensável para a inserção da criança na cultura. Entende-se, assim, que o pai possui um papel central na saúde psíquica dos filhos (Kehl, 2003). Cabe ressaltar, entretanto, que embora a função de rompimento do vínculo narcísico seja tradicionalmente associada ao pai, a função paterna não está necessariamente vinculada à presença de uma figura real do sexo masculino, mas a alguém ou algo que exerça tal função.

Aberatury e Salas (1984) chamaram atenção para o fato de que a psicanálise considera fundamental para a vida da criança que esta tenha sido desejada. Assim, os autores referem que "sentir-se filho do pai é tão fundamental para o desenvolvimento do indivíduo como o próprio fato de sê-lo" (p. 68). Seguindo nesta perspectiva, os autores referem que todo o bebê necessita de alguém que exerça a função paterna para poder desprender-se da mãe. Sabe-se que no período inicial, principalmente até os quatro meses de vida do bebê, o interesse do bebê se centraliza quase exclusivamente em sua mãe. No entanto, o exercício da função paterna será fundamental para o desenvolvimento psíquico do bebê.

Nesse sentido, cabe à figura paterna o reconhecimento do filho. Tal reconhecimento pode se iniciar com a nomeação do bebê. É com o nome, que traz dentro dele a marca de um sonho projetado para aquele bebê que acaba de chegar ao mundo, juntamente com o nome de família, que será marcada a inserção do sujeito dentro do grupo familiar. Entretanto, para além do nome, o filho precisa que o pai também lhe ofereça um lugar no mundo, a possibilidade de conhecer para poder ocupá-lo e o reconhecimento, tão importante para que o filho se sinta capaz e aproprie-se deste lugar (Corso \& Corso, 2011).

Para tanto, é importante que o pai encontre uma forma de se comunicar com o bebê, que lhe dê um lugar e seja compreendido pelo filho. Assim, torna-se também relevante que o pai se sinta encorajado a participar do cuidado com o bebê em tarefas como banhá-lo, brincar com ele e alimentá-lo, participando de seu desenvolvimento e facilitando os processos de identificação. Aberastury e Salas (1984) destacaram ainda a importância do pai na família, como sendo um dos caminhos para se pensar na profilaxia das neuroses infantis.

Outro aspecto que merece destaque se refere às vivências emocionais dos próprios pais frente à tarefa de exercer a paternidade. O nascimento de um filho traz consequências à subjetividade de seu genitor, uma vez que 
tornar-se pai acarreta emoções muito intensas, equivalentes àquelas que uniam o pai aos seus próprios pais na infância (Aberastury \& Salas, 1984; Bowlby, 1997; Zornig, 2010). Assim, o exercício da paternidade exige do homem uma entrega de afeto à criança e um desprendimento de si próprio que só são conquistados com a maturidade (Aberastury \& Salas, 1984).

Nesse sentido, Benczik (2011) chama atenção para a busca pelo novo pai de parâmetros de referência para guiar sua relação com o filho. Dessa forma, a relação estabelecida com o próprio pai pode ser ressignificada na relação atual pai-filho através da transmissão de valores, afeto e limites (Beltrame \& Bottoli, 2010; Zornig, 2010) ou, através de uma postura diferente da vivenciada na infância, rompendo com um modelo paterno sentido como frio e autoritário (Benczik, 2011).

Além disso, o homem se depara com uma demanda oriunda das exigências da contemporaneidade em relação ao seu papel como homem, como pai e como sujeito, existindo uma pressão para que seja mais participativo dentro dos lares (Gomes \& Resende, 2004; Souza \& Benetti, 2009; Staudt \& Wagner, 2008). Assim, a figura paterna também revive seus próprios conflitos, questões relativas às suas figuras parentais e o imperativo de presença, de corporalidade e afetividade diante do filho.

Dessa forma, o modelo paterno foi sofrendo alterações juntamente com as modificações ocorridas na sociedade (Benczik, 2011). A essas alterações, Corso e Corso (2011) defendem que a função paterna não deixou de existir enquanto figura de respeito e autoridade no contexto familiar, no entanto, ela passou por modificações, adequando-se aos moldes e necessidades da família nuclear, caracterizada por vínculos próximos entre pais e filhos (Amiralian, 2014; Ramires, 2014). Assim, é possível perceber que do pai contemporâneo espera-se que seja capaz de construir uma relação afetiva com seus filhos pautada na sua história de vida e na sua singularidade, transformando e reinventando seu papel através dos valores antigos e novos, sem desconsiderar os padrões apresentados pela sociedade atual (Beltrame \& Bottoli, 2010).

No que se refere aos estudos no cenário nacional, destaca-se as pesquisas de Silva e Piccinini (2007), que apontaram para um novo modelo de paternidade, em que a participação dos pais ultrapassa o sustento financeiro e o envolvimento em passeios e brincadeiras. Segundo os autores, os pais investigados participavam dos cuidados básicos dos filhos, dividindo as responsabilidades pela criança com a companheira. Concebe-se assim, um pai mais presente e identificado com as exigências contem- porâneas da família, que expõe sua face afetiva e próxima da intimidade cotidiana, contrapondo-se à concepção tradicional que exigia distanciamento físico e afetivo (Castoldi, Gonçalves \& Lopes, 2014; Gomes \& Resende, 2004; Sutter \& Bucher-Maluschke, 2008).

Nesse sentido, corroborando com estudos realizados por Ramires (1997; 2014), o novo pai caracteriza-se como um sujeito que apresenta vontade e necessidade de estar próximo e participar da criação dos filhos, voltando-se de modo significativo para o exercício da paternidade em paralelo a outros interesses. A esse novo modelo de pai, Sutter e Bucher-Maluschke (2008) denominam de paternidade participativa, referindo-se ao interesse que alguns pais apresentam em participar do cotidiano e do crescimento dos filhos, se envolvendo ativamente no cuidado destes, seja em relação à alimentação, saúde, lazer, higiene e educação, além de considerarem esse envolvimento tão importante quanto a carreira profissional.

Os estudos que envolvem a temática paterna também têm apontado que as mudanças contemporâneas no que tange ao papel do pai,têm sido possíveis também devido ao movimento por parte das mães visando à inserção dos homens como responsáveis pelos cuidados à criança. A mulher, que até algumas décadas ocupava o lugar de única responsável pelos cuidados da casa e da família e que exercia o papel de protetora, se desvanece para dar lugar à companheira que, por mais que esteja envolvida emocionalmente com os filhos, abstém-se do peso excessivo do papel materno para permitir a entrada de um terceiro (o pai) nos cuidados com os filhos (Castoldi, Gonçalves \& Lopes, 2014; Gomes \& Resende, 2004).

Nesse sentido, o presente estudo objetiva descrever e compreender as percepções de mães sobre o vínculo pai-bebê e sobre a participação paterna nos cuidados com o filho. Constituiu-se como parte de um estudo maior intitulado "Promoção de saúde a bebês atendidos em uma unidade de atenção básica: o olhar voltado para indicadores de risco clínico ao desenvolvimento infantil", que teve como objetivo investigar a relação mãe-bebê de participantes do Programa da Criança em uma Unidade Básica de Saúde. Para o presente estudo foram realizadas entrevistas com as mães, através das quais foi possível observar a importância atribuída por elas à relação pai-bebê.

Nesse sentido, pode-se pensar num movimento importante que parece indicar uma transformação do lugar tradicionalmente ocupado pelos pais, sobretudo neste momento inicial da vida dos bebês. Apresentar um pai que brinca com os bebês, que participa ativamente 
de seus cuidados, como a troca de fraldas, o banho, a alimentação, entre outros aspectos, mostra-se relevante, considerando-se que, por muito tempo, o pai foi negligenciado no contexto das relações iniciais progenitores-bebês, que dava destaque aos estudos envolvendo a mãe e a maternidade (Bottoli \& Arpini, 2011; Levandowski \& Piccinini, 2006; Orlandi \& Tonelli, 2005).

\section{Método}

\section{Participantes}

Este estudo foi realizado no Programa da Criança de uma Unidade Básica de Saúde. O referido Programa atende crianças na faixa etária de zero a dois anos de idade, onde são realizadas consultas mensais com duração de, aproximadamente, 30 minutos, em que a criança é acompanhada por acadêmicos e profissionais da enfermagem e psicologia, em uma proposta interdisciplinar. Os alunos e profissionais do núcleo da enfermagem realizam o acompanhamento da curva de crescimento e do estado vacinal da criança, bem como do seu desenvolvimento físico e motor, além de prestarem orientações aos pais quanto à alimentação, sono e cuidados de saúde. Os acadêmicos da psicologia, por sua vez, atentam para o desenvolvimento psíquico e para as relações iniciais pais-bebês, com o intuito de detectar e prevenir riscos ao desenvolvimento infantil, bem como qualificar essas relações. Além disso, busca ofertar um espaço de escuta para esses pais, auxiliando-os a lidar com as mudanças, receios e angústias que possam surgir a partir da parentalidade.

Participaram deste estudo onze mães cujos bebês encontravam-se na faixa etária de zero a oito meses incompletos, atendidos no Programa da Criança anteriormente referido. Acredita-se que essa fase inicial do desenvolvimento configura-se em uma etapa crucial na vida de uma criança, já que alicerça as bases do desenvolvimento futuro (Winnicott, 1958/2000; Spitz, 1965/1998). No momento do estudo, dez das onze mães entrevistadas residiam com o pai do bebê e a maioria delas dedicava-se prioritariamente aos cuidados da família e da casa. A idade das mães compreendeu a faixa dos 21 aos 38 anos, e grande parte delas já possuía outros filhos.

\section{Instrumentos}

Os dados foram coletados através de entrevistas semi-estruturaras e realizadas com cada uma das mães individualmente, as quais foram gravadas em áudio, para posterior transcrição. $\mathrm{O}$ roteiro da entrevista compreendeu os seguintes tópicos guias: a gestação; as primeiras semanas; a relação mãe-bebê; participação paterna e rede de apoio. Entende-se que esse tipo de entrevista fornece os dados básicos para a compreensão das relações existentes entre os atores sociais e as situações em que se encontram, sendo possível uma compreensão detalhada das crenças, atitudes, valores e motivações das pessoas em seus contextos sociais específicos (Gaskell, 2002).

As entrevistas foram realizadas por três pesquisadores, na própria Unidade Básica de Saúde, em uma

Tabela 1 - Caracterização da amostra

\begin{tabular}{|l|l|l|l|l|l|}
\hline Díade (D) & Idade do bebê & Sexo do bebê & Idade da mãe & $N^{\circ}$ de filhos & Ocupação da mãe \\
\hline D1 & 05 meses & Feminino & 25 anos & 01 & Dona de casa \\
D2 & 06 meses & Feminino & 28 anos & 01 & Dona de casa \\
D3 & 06 meses & Feminino & 22 anos & 02 & Dona de casa \\
D4 & 05 meses & Masculino & 45 anos & 03 & Comerciante \\
D5 & 04 meses & Masculino & 25 anos & 02 & Comerciante \\
D6 & 06 meses & Masculino & 38 anos & 03 & Dona de Casa \\
D7 & 06 meses & Masculino & 37 anos & 04 & Dona de Casa \\
D8 & 03 meses & Feminino & 22 anos & 02 & Dona de Casa \\
D9 & 04 meses & Masculino & 28 anos & 01 & Vendedora \\
D10 & 04 meses & Feminino & 29 anos & 04 & Dona de Casa \\
D11 & 07 meses & Masculino & 21 anos & 02 & \\
\hline
\end{tabular}


sala reservada para tal finalidade e concedida pelo responsável do local. Após o aceite das mães em participarem do estudo, agendou-se um horário com as mesmas para a entrevista. Salienta-se que grande parte das mães optaram por realizar a entrevista no mesmo dia que viriam ao Programa da Criança, logo após a consulta, de modo que, no momento da entrevista, as mães estavam acompanhadas dos bebês e, por vezes, dos outros filhos. Foi realizada uma entrevista com cada mãe, seguindo o roteiro descrito acima, com duração aproximada de 45 minutos. Após a discussão do material, realizou-se uma entrevista de devolução com cada uma das mães, onde pontuaram-se aspectos que apareceram na entrevista, tais como a comunicação entre a díade, o saber da mãe sobre o filho, a participação do pai e da rede de apoio, além da realização de orientações que pudessem qualificar essas relações. Este segundo momento teve duração de, aproximadamento, 30 minutos.

\section{Procedimentos éticos}

Este estudo foi estruturado considerando-se as exigências preconizadas na Resolução no 466/2012 do Conselho Nacional de Saúde (2012). Inicialmente, o projeto de pesquisa foi apresentado à Unidade Básica de Saúde e à equipe do Programa da Criança. Após a autorização do local, o projeto foi submetido ao Comitê de Ética em Pesquisa (CEP) da Instituição onde as pesquisadoras atuam. Com a aprovação do projeto de pesquisa pelo CEP (protocolo número CAAE: 0077.0.243.000-11), as mães foram convidas a participar mediante os esclarecimentos éticos e a assinatura do Termo de Consentimento Livre e Esclarecido (TCLE).

\section{Análise dos dados}

Após a transcrição das entrevistas, iniciou-se o procedimento de análise qualitativa de conteúdo dos dados (Bardin, 1977). Para a análise dos dados, num primeiro momento, foi realizada a leitura individual, atenta e detalhada de todas as entrevistas pelo grupo de pesquisadoras. Ao final, foi analisado o conjunto do material e definidas as categorias das temáticas, levando em conta os aspectos que mais se destacaram por repetições, força discursiva e/ou carga emocional. A partir disso, duas categorias temáticas foram identificadas, a saber: Relação afetiva pai/bebê e Participação paterna.

\section{Resultados e discussão}

\section{1) Relação afetiva pai-bebê}

Pôde-se identificar que os pais se fizeram presentes de maneira significativa no relato das mães que participaram do estudo. Essas reconheciam que o filho não era apenas seu, mas também do pai, na medida em que referiram que, para o filho, o pai era alguém especial. Neste sentido, as mães pareciam considerar o pai como importante para o filho, permitindo e possibilitando que ele ocupasse um lugar significativo na vida do bebê: "Se ele chega, ela abre o olho e abre aquele sorrisão e fica ali com ele (M1)"; "Ele chega, ela já se atira pra ele. (...) Deus o livre,(ele) chegar na porta, falar com ela, ela já fica bem louquinha, comeşa a dar com os braço e os pezinho, quer colo dele" (M2); (...) o pai chama e ela ergue os bracos e vem. Mas ela reconhece bem, os da casa ela reconhece bem, ela não é de estranhar as pessoas, mas vamos dizer que tu chegue para brincar com ela e chega o pai ou o irmão, ela vai dar mais atenção pra eles do que para ti. Entendeu? Ela reconhece (...) (M10)

Através do relato das mães, pôde-se perceber que para elas há uma relação afetiva estabelecida entre pai e filho, desde os primeiros meses do bebê. A respeito disso, é importante considerar o que Sutter e Bucher-Maluschke (2008) denominam de "pai nutridor", como sendo aquele que constrói uma relação próxima e empática com os filhos, dividindo com a mãe o cuidado e atendendo-lhes fisicamente e emocionalmente. Assim, o "pai nutridor" se caracterizaria por se diferenciar do pai tradicional, definido como aquele que é responsável pelo provimento do lar, por conceder permissões, disciplinar e, ocasionalmente, brincar e participar de momentos de lazer familiar.

Esta relação afetiva do pai com a criança, que supera e extrapola o papel tradicional de provedor e disciplinador, esteve presente no discurso das entrevistadas: "O pai mima bastante ela. Quando o pai chega deixo ela deitada na cama e vou tomar banho, e quando volto o pai está com ela no colo. (...) O pai diz que ela queria colo" (M1); (...) se duvida o pai dele que tá só com ele no colo, e ele diz. "ah tá, tu pega muito o nenê no colo, senão a mãe briga com o pai depois, porque senão depois como é que a mãe vai trabalha contigo, dai tu vai fica chorando, o pai não quer que tu chore, senão o pai ia passa contigo só no colo" (M4); "Ah, brinca com ele, bota ele no chão, bota na cama e fica brincando. Anda com ele em cima da motinho, sai pra fora, brinca assim, me ajuda. Aos domingos principalmente, porque ele 
está de folga, aí ele passa o dia inteiro com ele, ai ele me dá uma mão. Porque eu tenho o outro, ai ele fica domingo o dia inteiro com ele" (M11).

É importante destacar, além disso, que a construção de uma relação afetiva pai-bebê esteve muito presente, inclusive, no relato da mãe que estava separada do pai do bebê no momento do estudo. Este aspecto evidencia que esse pai estaria conseguindo manter as funções parentais mesmo após a dissolução conjugal: "Ele tá bem atencioso. Ele sempre foi, só que agora, quando eu tava gestante, ele tava mais distanciado. Agora, quando ele tá com o guri, ele chora. E vê o guri, e quer levar pra fica com ele" (M9); "Ele ficou meio triste no dia dos pais, que ele não ficou com o guri. Tava meio enjoado o guri, tava meio gripadinho. Ai eu disse: Não, não vou tirar no tempo - tava chovendo ainda - pra te levar pra ti aí. Tu sabe, tu tem um filho, teu filho é abençoado, ele te ama'. Ai ele fico mais tranqüilo, mais calmo. Mas agora ele quer levar" (M9).

Entretanto, pôde-se perceber que, em alguns casos, as mães relataram que o estabelecimento da relação afetiva inicial pai-bebê deu-se de forma mais lenta, se comparada à delas, que estavam em contato com o filho por um período maior de tempo devido à licença maternidade ou pelo fato de não trabalharem: "Mas ele é bobalhão (o pai), assim, porque às vezes ela faz. umas coisas que assim, sabe, eu já sei que ela vai faze, claro eu fico mais com ela, e ele diæ: mãe, mãe, vem correndo vê, sabe. Ele, é, ele gosta dela" (M1); "O pai da M., ele viaja. O R.(referindo-se ao pai do bebê) em casa é de sexta à segunda de manhã, até ele ficou uns dois, três meses, foi mais que ele passou. Então... eu disse pra ele "R., a M. não vai te reconbecer quando tu vir", mas não, ela é bem apegada com ele, ele brinca com ela" (M10); "Agora que ele aceiton a filha, que é a cara dele, agora é 'minha filha' pra cá, 'minha filha' pra lá" (M1). A este respeito, Lamb (2010) indicou que os pais mostram-se mais confortáveis interagindo com uma criança mais velha do que com bebês. Isto estaria relacionado a uma tendência de os pais, tradicionalmente, interagirem com as crianças mais velhas através de brincadeiras divertidas e impetuosas do que através de cuidados diários, o que se torna mais viável conforme as crianças se tornam um pouco maiores.

\section{2) Participação paterna}

A partir dos relatos das participantes, pôde-se perceber que, na compreensão das mães, além de estarem vinculados emocionalmente com os bebês, os pais participam de seus cuidados diários. A participação paterna nos cuidados com o filho pode ser compreendida como as tarefas que o pai desenvolve no dia-a-dia e que podem ser percebidas por qualquer pessoa, não implicando necessa- riamente o vínculo afetivo pai-filho (Falceto, Fernandes, Baratojo, \& Giugliani, 2008).

Tem-se observado um incentivo cada vez maior para que o pai se envolva com o filho e participe de seu desenvolvimento, desde antes do nascimento (Amiralian, 2014; Ramires, 2014; Saravia, Reinhard \& Souza, 2012). A este respeito, Benczik (2011) apontou que a presença do pai no momento do nascimento favoreceria seu envolvimento posterior com o bebê, como pode ser percebido na seguinte fala: "Comecei contar as dores, as contrações. E de noite o pai (marido) ajudou a cuidar, cada qual mais ansioso, esperando o bebê" (M6). Esse pai, tal como referido pela mãe entrevistada, parece estar cada vez mais presente e participativo, compartilhando as tarefas com a mulher. Nesse sentido é importante ressaltar a importância da mãe de permitir e facilitar que o pai ocupe esse lugar.

Após o nascimento dos bebês, os pais foram apresentados pelas mães, como participantes e interativos com os filhos, em especial no momento da alimentação, higiene, sono e brincadeiras: "Brinca, nana pra dormi, ou dá uma mamadeira, arruma a mamadeira, ele pega. Fralda ele ainda não conseguiu trocar" (M2); "Ah, ele faz mamá, ele muda. Antigamente ele não gostava de mudar quando ele tava cocô, mas agora ele já vai e muda e não tem mistério" (M4); "Ele brinca, ele pega no colo, e fala assim 'vamos passear"” (M8); "Troca fralda, cuida. Ai quando chega a hora do mamá ele fala 'ó, essa parte não é comigo' e me entrega" (M10).Estes achados vão ao encontro do estudo de Silva e Piccinini (2007) que apontou que os pais interagem com os filhos de diferentes formas, participando dos cuidados no momento da alimentação, banho, brincadeira, entre outros. Nesse mesmo sentido, Krob, Piccinini e Silva (2009), através de entrevistas com 20 pais primíparos aos dois meses de vida dos bebês, identificaram que todos os participantes se envolviam de alguma forma nos cuidados básicos do bebê e nas trocas afetivas. A maioria dos pais assumia tarefas de cuidado espontaneamente, referindo satisfação em ter um momento em que estavam presentes na rotina do bebê e pelo qual eram responsáveis. Além disso, destaca-se que grande parte dos pais referia ter certeza de que entendia o bebê, distinguia os diferentes tipos de choro, sabia o que o bebê queria e o que estava sentindo.

Além disso, no caso de haver mais de um filho, destaca-se a possibilidade de o pai modificar sua forma de participação no cuidado com os filhos com o passar do tempo, assumindo com esse bebê tarefas que não havia desempenhado até então: "Agora o pai já muda, porque daquelas lá ele nunca mudou, sempre teve presente, mas nunca mudou, nunca trocou fralda, nada. Desse aqui ele troca fralda, 
troca roupa" (M6); "E ele com ela é mais carinhoso. Ele é mais carinhoso, dá mais atenção, e já o meu menino não tanto" (M8). Dessa forma, respondendo às necessárias adaptações nos papéis e na dinâmica familiar advindas da chegada de um filho, pode-se identificar a presença de um pai diferente, mais participativo e envolvido emocionalmente com o bebê (Castoldi, Gonçalves \& Lopes, 2014; Piccinini, Pereira, Marin, Lopes, \& Tudge, 2007).

Apesar disso, no presente estudo, pode-se identificar que os bebês passam a maior parte do tempo com as mães devido à carga horária de trabalho dos pais. $\mathrm{O}$ tempo mais restrito, contudo, parece não se constituir em obstáculo para a participação do pai nos cuidados com o bebê. "O pai dele trabalha na $X$, ai chega de manhã e vai dormir. Só tem de tarde pra fica com eles. Pouco tempo. (...) Ah, ele dá atenção pra eles bastante" (M7); "Ele procura ajudar mais à noite, né, porque ele fica o dia todo no serviço. Ele tá só de noite. Ai ele chega, pega ela. Daí se ela tá meia choruminho ou quer colo, ele pega, brinca com ela, vai lá pra cama, fica com ela, entrete até eu fazer janta" (M2); "Tempo dele é quando ele chega do serviço. Domingo ele diz: 'Hoje tu não vai fazer nada. E hoje o negão é só meu"” (M5).

É pertinente destacar que, apesar da referência das mães à participação paterna nos cuidados ao bebê, pode-se perceber que elas continuam sendo a principal referência nos cuidados cotidianos deles. Devido ao tempo dedicado ao trabalho, os pais desempenham um papel que parece se constituir mais como fonte de apoio às necessidades da mãe e do filho (Castoldi, Gonçalves \& Lopes, 2014). Dessa forma, durante os momentos que está em casa, o pai cuida da criança para que a mãe consiga desempenhar atividades pessoais ou domésticas: "Ele dá uma mão, dá uma ajuda, tipo quando eu vou tomar banho, ou quando vou fazer comida. Nem sempre a criança tá disposta a ficar deitada, então, ele ajuda a cuidar. Mas ele pega, brinca com ela" (M8); "Quando ele vai na venda, e eu tenho que fazer o almoço, um negócio, ele pega e leva ele junto na venda, sai com ele pra eu poder fazer as coisas. Porque eu fico direto só com ele, até ele dormir, pra eu poder fazer as coisas, os serviços. Fica brincando com ele e com o outro" (M11).

No que tange às diferenças nos cuidados dispensados por pais e mães, o estudo de Sutter \& Bucher-Maluschke (2008) indicou que, apesar de vivenciarem sentimentos muito semelhantes aos das mães, os pais tenderam a descrever o cotidiano com o filho de um modo mais lúdico e prático, além de indicarem maior facilidade para frustrá-lo. Os próprios pais do estudo diferenciaram sua forma de se relacionar e cuidar dos filhos, não exercendo a paternidade de uma forma espe- lhada em suas esposas. Segundo os autores, o modelo de paternidade participativa - que não exclui a possibilidade de a mãe ser a principal cuidadora - refere-se à disposição do pai em se envolver ativamente no cuidado dos filhos, interessando-se em participar do cotidiano e do crescimento deles, considerando esta tarefa tão ou mais importante que a profissional.

Considerações finais

Apesar da relação afetiva pai-bebê ter sido apontada por algumas mães como se estabelecendo de forma mais lenta que o vínculo mãe-bebê, os resultados parecem indicar a existência de um pai que manifesta afeto para com o filho já nas relações iniciais. $O$ fato de o discurso materno atribuir um lugar importante ao pai na relação com o bebé é interessante, em especial, ao se considerar o contexto onde a pesquisa foi realizada, a saber, um serviço público de saúde. Assim, pode-se pensar que esse movimento que altera o lugar e a função do pai em relação aos filhos vem se consolidando em diferentes contextos, atingindo os diferentes grupos sociais.

Dessa forma, este estudo possibilitou, através do discurso das mães perceber o pai envolvido com os filhos não apenas na função de provedor, como tradicionalmente ocorria, mas vinculando-se afetivamente ao filho e participando ativamente dos cuidados à ele, seja nos momentos de alimentação e higiene, seja nos momentos de descontração e ludicidade. Assim, esse lugar ocupado pelos pais na relação com seus bebês foi apresentado pelas mães de foram favorável.

Por fim, destaca-se a importância de ações em promoção de saúde a fim de favorecerem a interação pai-bebê, fortalecendo os vínculos iniciais. Para tanto, se faz necessária uma atitude de acolhimento por parte dos profissionais que atuam nos serviços de saúde de forma a facilitar a inclusão e a participação paterna, abrindo espaço para que esses se manifestem e se sintam integrados nas intervenções voltadas à saúde do bebê e da família.

Por fim, ressalta-se que o presente estudo apresenta limitações, sobretudo em razão de ter considerado essa temática apenas na perspectiva das mães dos bebês. Assim, sugere-se a realização de novos estudos que possam ter o pai ou a família como participante, ampliando a compreensão sobre o tema envolvendo as relações iniciais no contexto familiar.

\section{Referências Bibliográficas}

Amiralian, M. L. M. (2014). O pai nos dias de hoje e as consequências para o desenvolvimento. In: Rosa, C. D. (Org.) E o Pai? Uma abordagem Winnicotiana. São Paulo: D.W.W Editorial. p. 127-140. 
Aberastury A. \& Salas E. J. (1984). A paternidade: um enfoque psicanalítico (M. N. Folberg, Trans.). Porto Alegre: Artes Médicas.

Bardin, L. (1977). Análise de conteúdo (70ª ed.) (L. A. Reto \& A. Pinheiro, Trans.). Lisboa: Edições.

Beltrame, G. \& Bottoli, C. (2010). Retratos do envolvimento paterno na atualidade. Barbarói, $s / v(32), 205-26$.

Benczik, E. B. P. (2011). A importância da figura paterna para o desenvolvimento infantil. Revista Psicopedagogia, 28(85),67-75.

Bottoli, C. \& Arpini, D. M. (2011). O exercício da paternidade na separação conjugal. In: Jaeger, F. P.,

Kruel, C. S., \& Siqueira, A. C. Parentalidade contemporânea: os desafios para a psicologia. Santa Maria: Centro Universitário Franciscano.p. 123-150.

Bowlby, J. (1997). Formação e rompimento dos laços afetivos. (3a ed). (A. Cabral, Trad.). São Paulo: Martins Fontes.

Castoldi, L.; Gonçalves, T. R. \& Lopes, R. C.S.( 2014). Envolvimento paterno da gestação ao primeiro ano de vida do bebê. Psicologia em Estudo,19(2), 247-259.

Conselho Nacional de Saúde (2012). Resolução do Conselho Nacional de Saúde 466/12. Recuperado em 12 nov. de 2013, em http://conselho.saude.gov. br/resolucoes/2012/Reso466.pdf.

Corso, D. \& Corso, M. (2011). A psicanálise na terra do nunca: ensaios sobre a fantasia. Porto Alegre: Penso.

Dias, A. B. \& Aquino, E. M. L. (2006). Maternidade e paternidade na adolescência: algumas constatações em três cidades do Brasil. Caderno de Saúde. Pública, 22(7), 1447-58.

Falceto, O. G., Fernandes, C. L., Baratojo, C., \& Giugliani, E. R. J. (2008). Fatores associados ao envolvimento do pai nos cuidados do lactente. Revista Saúde Pública, 42(6), 1034-40.

Gaskell, G. (2002). Entrevistas individuais e grupais. In: W. Bauer \& G. Gaskell (Eds.). Pesquisa qualitativa com texto, imagem e som: um manual prático. Petrópolis: Vozes, p. 64-89.

Gomes, A. J. S. \& Resende, V. R. (2004). O pai presente: o desvelar da paternidade em uma família contemporânea. Psicologia: Teoria e Pesquisa, 20(2), $119-125$.

Julien, P. (2000). Abandonarás teu pai e tua mãe. Rio de Janeiro: Companhia de Freud.

Kehl, M. R. (2003). Em defesa da família tentacular. In: G. Groeninga \& R. Pereira. Direito de Família e Psicanálise. Rio de Janeiro: Imago, p. 163-176.

Krob, A. D., Piccinini, C. A., \& Silva, M. R. (2009). A transição para a paternidade: da gestação do segundo mês de vida do bebê. Psicologia USP, 20(2), 269-91.

Lamb, M. (2010). The role of the father in child development. 5nd ed. Hoboken: Wiley.

Levandowski, D. C. \& Piccinini, C. A. (2006). Expectativas e sentimentos em relação à paternidade entre adolescentes e adultos. Psicologia: Teoria e Pesquisa, 22(1),17-28.
Muza, G. M. (1998). Da proteção generosa à vítima do vazio. In: P. Silveira (Org.), Exercício da paternidade. Porto Alegre: Artes Médicas, p. 143-150

Nelson, T. J. (2004). Low-income fathers. Ann. Rev. of Sociol., s/v(s/n), 427-51.

Orlandi R. \& Tonelli, M. J. F. (2005). Sobre o processo de constituição do sujeito face à paternidade na adolescência. Psicologia em Revista, 11(18), 257-67.

Piccinini, C., Pereira, C., Marin, A., Lopes, R., \& Tudge, J. (2007). O nascimento do segundo filho e as relações familiares. Psicologia: Teoria. e Pesquisa., 23(3), 253-62.

Ramires, V. R. (1997). O Exercício da Paternidade Hoje. Rio de Janeiro: Rosa dos Tempos.

Ramires, V. R. (2014). A paternidade na contemporaneidade. In: Arpini, D. M. \& Cúnico, S. D. (Orgs.). Novos olhares sobre a família: aspectos psicológicos, sociais e jurídicos. Curitiba: CRV. p. 27-38.

Roudinesco, E. (2003). A família em Desordem. Rio de Janeiro: Jorge Zahar.

Saraiva, L. M.; Reinhard, M. C. \& Souza, R. C. (2012). A função paterna e seu papel na dinâmica familiar e no desenvolvimento infantil. Revista Brasileira de Psicoterapia, 14(3), 52-67.

Silva, M. R. (2007). Paternidade e depressão pós-parto materna no contexto de uma psicoterapia breve pais-bebê. Unpublished doctoral dissertation. Programa de Pós-Graduação em Psicologia do Desenvolvimento. Instituto de Psicologia, UFRGS. Porto Alegre, Brasil.

Silva, M. R. \& Piccini, C. A. (2007). Sentimentos sobre a paternidade e o envolvimento paterno: um estudo qualitativo. Estudos de Psicologia, 24(4), 561-73.

Souza, C. \& Benetti, S. (2009). Paternidade contemporânea: levantamento da produção acadêmica no período de 2000 a 2007. Paidéia, 19(42), 97-106.

Spitz, R. A. (1965-1998). O primeiro ano de vida (E. M. B. Rocha, Trans.). São Paulo: Martins Fontes.

Staudt, A. C. \& Wagner, A. (2008). Paternidade em tempos de mudança. Psicologia: Teoria \& Prática, 10(1),174-85.

Sutter. C. \& Bucher-Maluschke, J. (2008). Pais que cuidam dos filhos: a vivência masculina na paternidade participativa. Psico, 39(1),74-82.

Wagner, A, Predtebon, J., Mosmann, C., \& Verza, F. (2005). Compartilhar tarefas? Papéis e funções de pai e mãe na família contemporânea.Psicologia: Teoria e Pesquisa, 21(2), 181-186.

Wendland, J. (2001). Abordagem clínica das interações pais-bebê: perspectivas teóricas e metodológicas. Psicologia Reflexão e Crítica, 14(1),45-56.

Winnicott, D. W. (1958-2000). Da pediatria à psicanálise: obras escolbidas (D. Bogomoletz, Trans.). Rio de Janeiro: Imago.

Zornig, S. M. (2010). Tornar-se pai, tornar-se mãe: o processo de construção da parentalidade. Tempo psicanalítico, 42(2), 453-470.

Submetido em: 7-5-2017

Aceito em: 29-11-2017 